\title{
Ménétrier's disease with normal albumin level
}
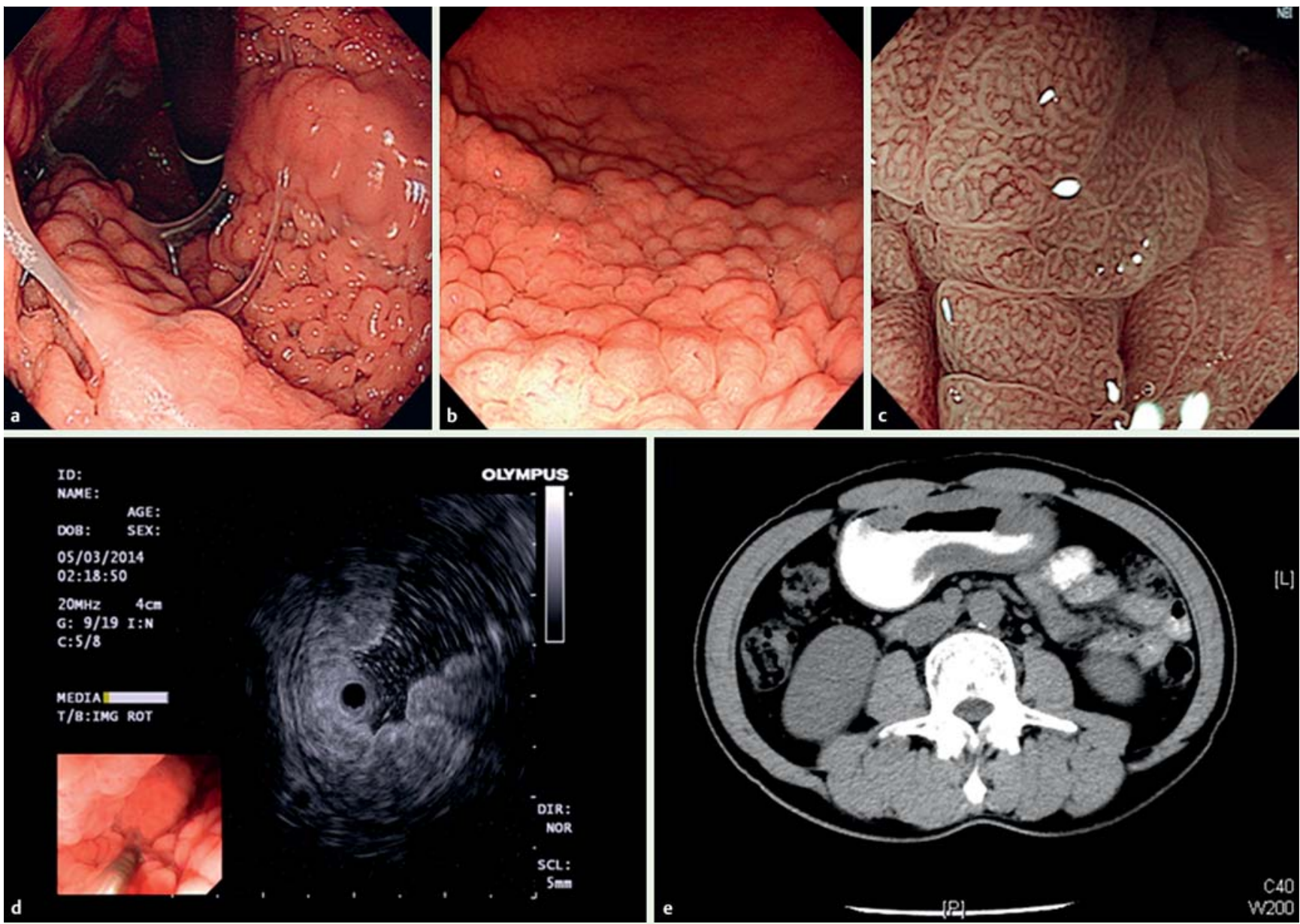

Fig. 1 Ménétrier's disease. a, b Endoscopic views of the stomach under white light. c Narrow-band imaging of the hypertrophic mucosa. Ultrasonic (d) and computed tomographic (e) views of the stomach.

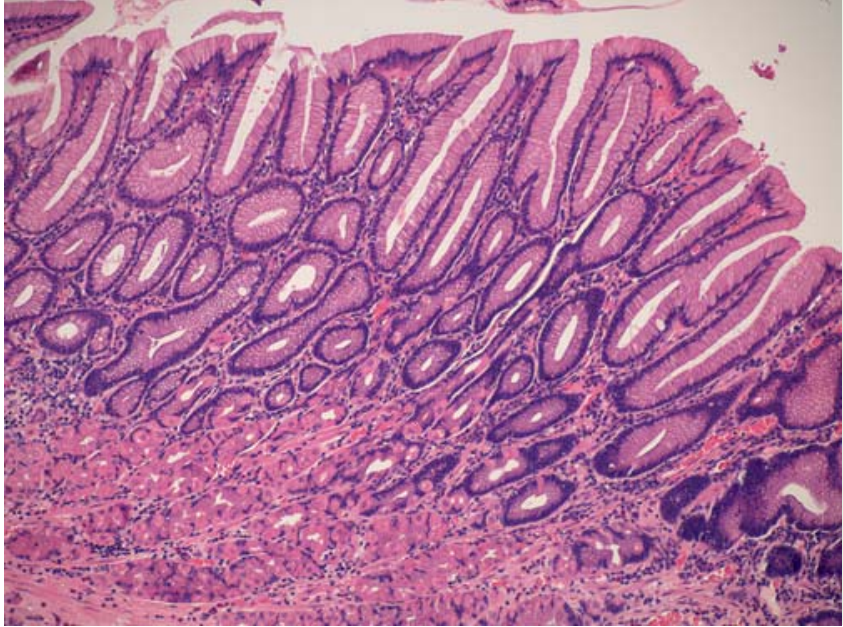

A 49-year-old man presented with a 5month history of epigastric distension after meals. He had no history of abdominal pain, nausea, vomiting, or diarrhea and no family history of cancer. The phys-
Fig. 2 Histology of the biopsy specimen.

ical examination was negative for edema, ascites, and superficial lymph nodes. Helicobacter pylori infection was detected with the carbon 13 urea breath test. Gastroscopy showed diffuse hypertrophic gastric mucosa covered by excessive mucus and limited to the stomach body and fundus $(\bullet$ Fig. 1 a, b). A regular pit pattern of the hypertrophic mucosa was observed on narrow-band imaging ( $\bullet$ Fig. $1 \mathrm{c}$ ). Ultrasonic endoscopy revealed a thickened mucosal layer ( $\bullet$ Fig. 1 d). Computed tomography confirmed these findings and showed no palpable abdominal lymph nodes ( $\bullet$ Fig. 1 e). Histology of full-thickness biopsy specimens showed marked foveolar epithelial hyperplasia and no malignant cells ( Fig.2). The patient's total serum protein, albumin, gastrin, and immunoglobulin G (subtypes IgG1 - IgG4) were normal, as well as the blood cell count. Therefore, Ménétrier's disease was diagnosed.

Ménétrier's disease is a rare, idiopathic hypertrophic gastropathy characterized by hyperproliferative foveolar epithelium of the stomach body and fundus and 
hypoproteinemia [1]. Ménétrier’s disease should be distinguished from gastric polyposis syndrome, hyperplasic gastritis, Zollinger-Ellison syndrome, and gastric malignancy $[1,2]$. In this case, the patient had a normal albumin level, indicating that the secretion of mucus had not resulted in hypoproteinemia. In addition, the Ménétrier's disease was associated with $H$. pylori infection $[3,4]$. Therefore, treatment to eradicate $H$. pylori was initiated. After 1 month, the patient's symptoms were alleviated, his body weight increased $2.5 \mathrm{~kg}$, and the secretion of mucus decreased; however, there was no regression of the hypertrophic gastric mucosa.

Endoscopy_UCTN_Code_CCL_1AB_2AD_3AD

Competing interests: None
Lang Yang, Xiaojun Zhao, Ai-qin Li, Jian-qiu Sheng

Department of Gastroenterology, General Hospital of Beijing Military

Command, Beijing, China

\section{References}

1 Lambrecht NW. Ménétrier's disease of the stomach: a clinical challenge. Curr Gastroenterol Rep 2011; 13: 513-517

2 Rich A, Toro TZ, Tanksley J et al. Distinguishing Ménétrier's disease from its mimics. Gut 2010; 59: 1617-1624

3 Bayerdörffer E, Ritter MM, Hatz R et al. Healing of protein losing hypertrophic gastropathy by eradication of Helicobacter pylori is Helicobacter pylori a pathogenic factor in Ménétrier's disease? Gut 1994; 35: 701 714

4 Fretzayas A, Moustaki M, Alexopoulou E et al. Menetrier's disease associated with Helicobacter pylori: three cases with sonographic findings and a literature review. Ann Trop Paediatr 2011; 31: 141 - 147
Bibliography

Dol http://dx.doi.org/

10.1055/s-0034-1377983

Endoscopy 2015; 47: E9-E10

(c) Georg Thieme Verlag KG

Stuttgart · New York

ISSN 0013-726X

\section{Corresponding author}

\section{Jian-qiu Sheng, MD, PhD}

Department of Gastroenterology

General Hospital of Beijing Military Command

Nanmencang 5\#, Dongcheng District

Beijing 100700

China

Fax: +86-10-66721299

jianqiu@263.net 